\title{
The Crystal Structure of $\boldsymbol{N}$-(2-Hydroxyethyl)-octadecanamide
}

\author{
BIRGITTA DAHLÉN,* IRMIN PASCHER and STAFFAN SUNDELL
}

Department of Structural Chemistry, Institute of Medical Biochemistry, Univérsity of Göteborg P.O.B. S-400 33 Göteborg 33, Sweden

$N$-(2-Hydroxyethyl)-octadecanamide ( $N$-stearoylethanolamine) crystallizes in the space group $P c$ with the cell constants $a=47.588, b=4.886$, $c=8.999 \AA$ and $\beta=93.71^{\circ}$. There are two molecules in the asymmetric unit but parts of the hydrocarbon chains are related by a pseudo centre of symmetry. The molecules are $V$-shaped $\left(131^{\circ}\right)$ with a bend at the $\beta$-carbon atom in the fatty acid chain. The molecules are arranged in double layers and linked together by one $\mathrm{N}-\mathrm{H} \cdots \mathrm{O}$ and one $\mathrm{O}-\mathrm{H} \cdots \mathrm{O}$ hydrogen bond both running in the $b$ axis direction. The chain packing is of the orthorhombic type $\mathrm{O}_{\underline{1}}$. The chain axes are tilted by $55.5^{\circ}$ to the end group planes.

$N$-Acylethanolamines of long-chain fatty acids have been isolated from the non-saponifiable lipid fraction of soya lecithin, peanuts and egg yolk. ${ }^{1}$ They were later also detected among the lipids of bovine kidney..$^{2}$ It has not so far been established with certainty whether $N$. acylethanolamines as such are essential constituents in cells, or if they are degradation products possibly arising from sphingolipid metabolism ${ }^{3,4}$ or by saponification of unknown precursors. They may in part, also be mere artifacts derived from cephalins during alkaline treatment. ${ }^{5}$

Physicochemical investigations on membrane lipids performed at this Department also include systematical studies of the lipophilic or polar parts of complex lipid molecules. Thus the conformation and molecular packing of, e.g., sphingolipid components such as sphingo$\sin \theta^{6}$ tetracosanoylphytosphingosine ${ }^{7}$ and neuraminic acid ${ }^{8}$ have been established by single crystal work. $N$-Acylethanolamines are of interest in this context as both an amide

* To whom correspondence should be addressed. bound fatty acid and a hydroxyl group at adjacent carbon atoms of an amino alcohol are characteristic for ceramides which constitute the lipophilic part of all sphingolipids.

\section{CRYSTAL DATA}

Molecular formula $\quad \mathrm{C}_{20} \mathrm{H}_{41} \mathrm{NO}_{2} ; N \cdot(2$-hydroxyethyl)-octadecanamide

Unit cell, monoclinic $a=47.588(10), b=4.886(2)$, $c=8.999(2) \AA, \beta=93.71(2)^{\circ}$ $V \quad 2088.0 \AA^{3}$

Molecular weight $\quad 327.55$

$Z$

$\dot{D}_{\mathrm{c}} \quad 1.042 \mathrm{~g} \mathrm{~cm}^{-3}$

$\lambda \quad 1.54051 \AA\left(\mathrm{CuK \alpha _{1 }}\right.$ radia-

Systematically absent tion)

reflexions $\quad h 0 l l=2 n+1$

Space group $\quad P c$

\section{EXPERIMENTAL}

$N$-(2-Hydroxyethyl)-octadecanamide ( $N$-stearoylethanolamine),

$\mathrm{CH}_{3}-\left(\mathrm{CH}_{2}\right)_{18}-\mathrm{CO}-\mathrm{NH}-\mathrm{CH}_{2}-\mathrm{CH}_{2}-\mathrm{OH}$,

was synthesized by selective $N$-acylation of ethanolamine with $p$-nitrophenyloctadecanoate. The compound crystallizes from acetone in elongated prisms which on heating undergo a phase transition at $78-84^{\circ} \mathrm{C}$. DPT-diagrams * show an increase of long-spacings from 47.6 to $50.5 \AA$ and a transition of the chain packing from orthorhombic $\mathrm{O} \perp$ to hexagonal, indicated by a broad short-spacing line at $4.16 \AA$. On further heating the crystals melt abruptly at $103.2-103.4^{\circ} \mathrm{C}$.

* Diffraction pattern recorded continuously as a function of temperature. 
A single crystal with dimensions $0.04 \times 0.44 \times$ $0.39 \mathrm{~mm}$ was mounted along the $b$ axis. Data were collected on a Picker FACS I automatic diffractometer using graphite monochromated $\mathrm{Cu} K \alpha$ radiation. The $\theta-2 \theta$ scanning mode was used to measure the reflexions at a scanning rate of $2^{\circ} \mathrm{min}^{-1}$ and a scan width of 2.75 degrees. $10 \mathrm{~s}$ background counts were taken at both ends of the scan range for each reflexion. A total of 2622 reflexions having $2 \theta$ less than $110^{\circ}$ were recorded. 728 of these intensities were less than $2 \sigma$ above background and excluded from the calculations.

Corrections for the Lorentz and polarization effects were applied but not for absorption.

\section{STRUCTURE DETERMINATION AND REFINEMENT}

The Weissenberg photographs as well as the diffractometer data showed that the crystals were monoclinic with a $c$-glide plane. However, it was not clear if $0 k 0$ reflexions with $k$ odd were absent. A Wilson plot was calculated from which it was not possible to decide whether the space group was centric or acentric. The unit cell contained four molecules and initially the space group was assumed to be $P 2_{1} / c$.

From a sharpened three-dimensional Patterson synthesis the carbon chain direction was clearly shown. With the information given in the Patterson map the carbon atoms in the fatty acid chain were located and structure factor and electron density calculations were performed. The $R$-factor was around 0.5 , but the individual agreement between observed and calculated structure factors indicated that the chain was correctly placed. However, it was impossible to locate the rest of the atoms. It was therefore assumed that the molecules crystallized in the acentric space group $P c$ with two independent molecules in the asymmetric unit. The carbon atoms in the fatty acid chain in the second molecule were given positions as if a symmetry centre existed as it was considered that the deviations from $P 2_{1} / c$ were due to the polar part. From the next few Fourier syntheses the missing atoms were easily located. It was hereby found that only 15 of the atoms of the fatty acid chain were related by the non-crystallographic centre of symmetry and that these atoms corresponded to different chain parts in related molecules. After three cycles of block-diagonal refinement
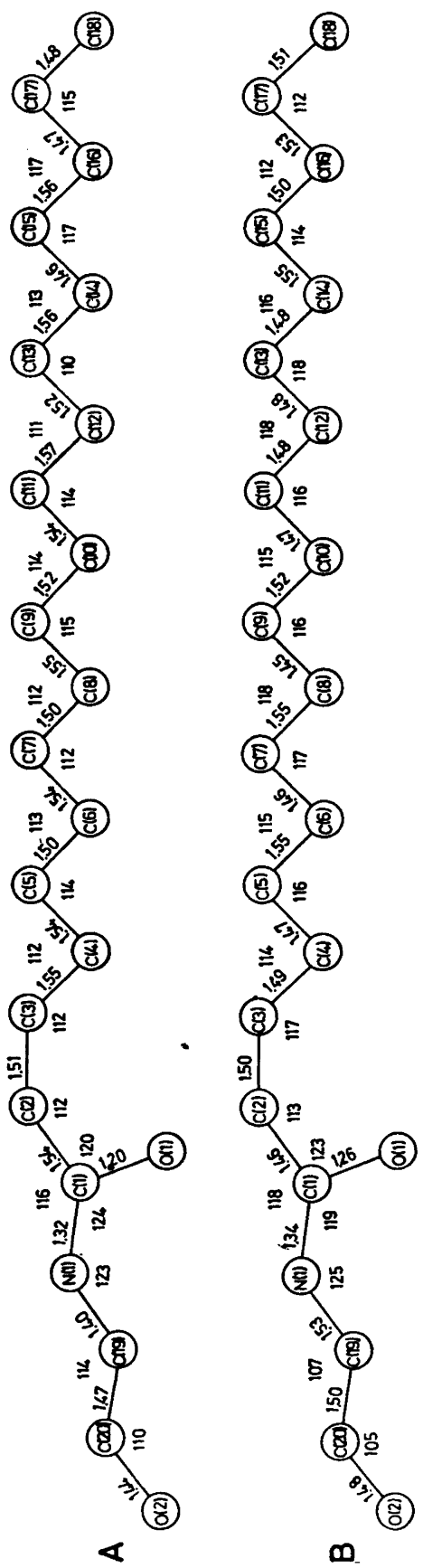

Fig. 1. Bond lengths and angles.

varying the positional parameters and the isotropic temperature factors for all 46 atoms the $R$-factor was 0.16 .

Acta Chem. Scand. A 31 (1977) No. 4 
Table 1. Fractional atomic coordinates with standard deviations for the non-hydrogen atoms.

$x$

$y$

Molecule A

C(1)

C(2)

$0.075(1)$

$0.097(1)$

$0.126(1)$

$0.139(1)$

$\mathrm{C}(4)$

$\mathrm{C}(5)$

C(6)

$\mathrm{C}(7)$

C(8)

$\mathrm{C}(9)$

$\mathrm{C}(10)$

C(11)

C(12)

C(13)

C(14)

C(15)

C(16)

C(17)

C(18)

$\mathrm{C}(19)$

$\mathrm{C}(20)$

$\mathrm{N}(1)$

$\mathrm{O}(1)$

0.169 (1)

$0.183(1)$

$0.213(1)$

$0.227(1)$

$0.256(1)$

$0.272(1)$

$0.301(1)$

$0.317(1)$

$0.346(1)$

$0.362(1)$

0.389 (1)

$0.407(1)$

0.435 (1)

$0.451(1)$

0.039 (1)

$0.011(1)$

0.060 (1)

$0.072(1)$

$O(2)$

$-0.009(1)$

Molecule B

\begin{tabular}{llll}
$\mathrm{C}(1)$ & $0.883(1)$ & $0.201(2)$ & $1.369(3)$ \\
$\mathrm{C}(2)$ & $0.862(1)$ & $0.289(2)$ & $1.470(3)$ \\
$\mathrm{C}(3)$ & $0.833(1)$ & $0.185(3)$ & $1.425(3)$ \\
$\mathrm{C}(4)$ & $0.819(1)$ & $0.297(2)$ & $1.284(3)$ \\
$\mathrm{C}(5)$ & $0.791(1)$ & $0.190(2)$ & $1.246(3)$ \\
$\mathrm{C}(6)$ & $0.775(1)$ & $0.309(2)$ & $1.103(3)$ \\
$\mathrm{C}(7)$ & $0.747(1)$ & $0.195(3)$ & $1.068(3)$ \\
$\mathrm{C}(8)$ & $0.730(1)$ & $0.307(3)$ & $0.928(3)$ \\
$\mathrm{C}(9)$ & $0.702(1)$ & $0.196(2)$ & $0.892(3)$ \\
$\mathrm{C}(10)$ & $0.686(1)$ & $0.312(3)$ & $0.754(3)$ \\
$\mathrm{C}(11)$ & $0.658(1)$ & $0.197(2)$ & $0.719(3)$ \\
$\mathrm{C}(12)$ & $0.643(1)$ & $0.309(2)$ & $0.585(3)$ \\
$\mathrm{C}(13)$ & $0.614(1)$ & $0.197(3)$ & $0.543(3)$ \\
$\mathrm{C}(14)$ & $0.599(1)$ & $0.306(3)$ & $0.407(3)$ \\
$\mathrm{C}(15)$ & $0.568(1)$ & $0.196(3)$ & $0.375(3)$ \\
$\mathrm{C}(16)$ & $0.554(1)$ & $0.310(3)$ & $0.236(3)$ \\
$\mathrm{C}(17)$ & $0.524(1)$ & $0.189(4)$ & $0.203(3)$ \\
$\mathrm{C}(18)$ & $0.510(1)$ & $0.309(5)$ & $0.065(3)$ \\
$\mathrm{C}(19)$ & $0.921(1)$ & $0.337(3)$ & $1.200(3)$ \\
$\mathrm{C}(20)$ & $0.948(1)$ & $0.256(4)$ & $1.291(3)$ \\
$\mathrm{N}(1)$ & $0.899(1)$ & $0.393(2)$ & $1.308(3)$ \\
$\mathrm{O}(1)$ & $0.887(1)$ & $-0.047(2)$ & $1.336(3)$ \\
$\mathrm{O}(2)$ & $0.969(1)$ & $0.199(2)$ & $1.182(3)$ \\
\hline
\end{tabular}

A Fourier difference synthesis was then calculated from which all hydrogens except H 17 in molecule A (Fig. 1) were located. The hydrogen atoms were included in the calculations and given the same isotropic temperature factor as the parent atom. Due to the large number of atoms in relation to the number of reflexions only the hydrogen atoms attached to the oxygen and nitrogen atoms were refined. (The positions of the remaining hydrogen atoms were, however, redetermined from a difference map at the end of the refinement).

In the block-diagonal refinement anisotropic temperature factors for all non-hydrogen atoms were used lowering the $R$-value to 0.09 . A Fourier difference map now revealed the missing hydrogen atom, whereafter the structure was refined with full matrix methods. At first the two molecules were refined in separate runs due to the large number of parameters. However, as parts of the molecules are related by non-crystallographic symmetry the refinement did not proceed satisfactorily. A bond distance in one molecule is thus too long while the corresponding distance in the second molecule is too short. The parameters were then manually adjusted and for a few cycles all positional parameters were refined simultaneously using the full matrix. This, however, gave similar results as before. The refinement was terminated at an $R$-value of 0.067 . Individual distances and angles deviate, for the above mentioned reasons, seemingly considerably from the normal values but this is not significant as the standard deviations are large. No programs allowing constrained refinement were available.

Atomic scattering factors for carbon, nitrogen and oxygen atoms were taken from International Tables for X-Ray Crystallography, while for hydrogen atoms the values given by Stewart, Davidson and Simpson ${ }^{10}$ were used.

All calculations have been performed on a Datasaab D21-PDP 15 dual computer with the program system developed at this Department.

\section{DESCRIPTION OF THE STRUCTURE}

The positional parameters are given in Tables 1,2 and 3. Interatomic distances and angles are given in Fig. 1 where the atomic numbering is also indicated. The mean $\mathrm{C}-\mathrm{C}$ bond distance in the fatty acid chain is $1.51 \AA$ and the mean 
Table 2. Anisotropic thermal parameters in the form $\exp \left[-2 \pi^{2}\left(h^{2} a^{* 2} U_{11}+k^{2} b^{* 2} U_{22}+l^{2} c^{* 2} U_{33}+\right.\right.$ $\left.\left.2 k l b^{*} c^{*} U_{23}+2 l h a^{*} c^{*} U_{31}+2 h k a^{*} b^{*} U_{12}\right)\right]$. Standard deviations are given in parentheses. All values have been multiplied by $10^{3}$.

\begin{tabular}{|c|c|c|c|c|c|c|}
\hline & $U_{11}$ & $U_{22}$ & $U_{33}$ & $U_{23}$ & $U_{31}$ & $U_{12}$ \\
\hline \multicolumn{7}{|c|}{ Molecule A } \\
\hline $\begin{array}{l}C(1) \\
C(2) \\
C(3) \\
C(4) \\
C(5) \\
C(6) \\
C(7) \\
C(8) \\
C(9) \\
C(10) \\
C(11) \\
C(12) \\
C(13) \\
C(14) \\
C(15) \\
C(16) \\
C(17) \\
C(18) \\
C(19) \\
C(20) \\
N(1) \\
O(1) \\
O(2)\end{array}$ & $\begin{array}{l}30(5) \\
41(6) \\
31(5) \\
31(6) \\
25(5) \\
30(6) \\
22(5) \\
23(5) \\
53(7) \\
54(8) \\
20(5) \\
67(8) \\
49(7) \\
35(6) \\
63(7) \\
82(8) \\
67(6) \\
66(8) \\
41(7) \\
58(8) \\
29(4) \\
68(5) \\
84(6)\end{array}$ & $\begin{array}{l}61(6) \\
51(5) \\
59(5) \\
66(6) \\
64(6) \\
58(5) \\
44(5) \\
50(5) \\
68(6) \\
51(5) \\
62(5) \\
61(6) \\
57(5) \\
56(5) \\
57(5) \\
57(6) \\
67(6) \\
99(9) \\
44(5) \\
73(7) \\
30(4) \\
12(3) \\
68(6)\end{array}$ & $\begin{array}{r}26(4) \\
36(4) \\
35(4) \\
45(5) \\
40(4) \\
45(5) \\
57(5) \\
40(5) \\
22(4) \\
47(5) \\
46(5) \\
39(5) \\
53(5) \\
41(5) \\
50(5) \\
38(5) \\
42(5) \\
71(7) \\
63(6) \\
58(6) \\
61(5) \\
104(5) \\
184(9)\end{array}$ & $\begin{array}{r}-11(4) \\
10(4) \\
23(4) \\
-1(4) \\
-9(4) \\
-7(4) \\
0(4) \\
8(4) \\
-15(4) \\
2(5) \\
-2(4) \\
-18(4) \\
-6(5) \\
-8(4) \\
-2(5) \\
2(4) \\
1(5) \\
6(6) \\
14(5) \\
13(5) \\
6(4) \\
-20(3) \\
14(6)\end{array}$ & $\begin{array}{r}-7(3) \\
-20(4) \\
-6(4) \\
-13(4) \\
-5(4) \\
-13(4) \\
2(4) \\
-5(4) \\
-4(4) \\
-8(5) \\
-16(4) \\
-19(5) \\
-13(5) \\
-13(4) \\
-12(5) \\
-15(5) \\
-4(4) \\
-38(6) \\
8(5) \\
9(6) \\
5(3) \\
8(4) \\
65(6)\end{array}$ & $\begin{array}{r}1(5) \\
28(5) \\
-1(4) \\
11(5) \\
3(4) \\
26(5) \\
-7(4) \\
-5(4) \\
6(5) \\
-14(5) \\
-7(4) \\
6(6) \\
-3(5) \\
-7(4) \\
1(5) \\
-9(6) \\
-9(5) \\
6(7) \\
-4(5) \\
8(6) \\
7(4) \\
-10(3) \\
18(5)\end{array}$ \\
\hline \multicolumn{7}{|c|}{ Molecule B } \\
\hline $\begin{array}{l}C(1) \\
C(2) \\
C(3) \\
C(4) \\
C(5) \\
C(6) \\
C(7) \\
C(8) \\
C(9) \\
C(10) \\
C(11) \\
C(12) \\
C(13) \\
C(14) \\
C(15) \\
C(16) \\
C(17) \\
C(18) \\
C(19) \\
C(20) \\
N(1) \\
O(1) \\
O(2)\end{array}$ & $\begin{array}{l}51(5) \\
71(6) \\
46(4) \\
55(5) \\
59(5) \\
67(5) \\
68(6) \\
56(5) \\
39(4) \\
31(4) \\
67(5) \\
30(4) \\
50(5) \\
55(5) \\
41(4) \\
39(4) \\
53(5) \\
53(6) \\
82(8) \\
64(6) \\
73(5) \\
76(4) \\
58(4)\end{array}$ & $\begin{array}{r}9(3) \\
37(4) \\
36(4) \\
19(3) \\
28(3) \\
24(3) \\
43(4) \\
39(4) \\
26(3) \\
37(4) \\
.31(4) \\
33(3) \\
43(4) \\
43(4) \\
47(4) \\
49(4) \\
83(7) \\
116(8) \\
64(6) \\
82(7) \\
21(3) \\
33(3) \\
69(5)\end{array}$ & $\begin{array}{r}61(5) \\
36(4) \\
45(4) \\
38(4) \\
41(4) \\
43(4) \\
31(4) \\
47(4) \\
51(4) \\
45(4) \\
44(4) \\
51(4) \\
37(4) \\
55(4) \\
55(4) \\
66(5) \\
81(6) \\
75(6) \\
60(5) \\
132(9) \\
71(4) \\
74(3) \\
109(5)\end{array}$ & $\begin{array}{r}2(3) \\
-18(3) \\
-6(3) \\
1(3) \\
11(3) \\
7(3) \\
0(3) \\
-5(3) \\
12(3) \\
2(3) \\
8(3) \\
14(3) \\
7(3) \\
1(4) \\
2(4) \\
5(4) \\
-5(5) \\
8(6) \\
-5(4) \\
23(6) \\
-16(3) \\
6(3) \\
-5(4)\end{array}$ & $\begin{array}{r}-2(4) \\
3(4) \\
5(3) \\
-1(3) \\
2(3) \\
3(4) \\
-9(4) \\
1(4) \\
-1(3) \\
-6(3) \\
6(4) \\
3(3) \\
-4(3) \\
-6(4) \\
-14(3) \\
-7(4) \\
-24(5) \\
-11(5) \\
-13(5) \\
31(6) \\
17(3) \\
11(3) \\
38(4)\end{array}$ & $\begin{array}{r}1(3) \\
-31(4) \\
3(3) \\
-6(3) \\
3(3) \\
-21(3) \\
4(4) \\
2(4) \\
-8(3) \\
10(3) \\
8(4) \\
-4(3) \\
3(3) \\
7(4) \\
6(4) \\
10(4) \\
3(5) \\
5(6) \\
14(5) \\
3(5) \\
3(3) \\
18(3) \\
-9(4)\end{array}$ \\
\hline
\end{tabular}

$\mathrm{C}-\mathrm{C}-\mathrm{C}$ angle is $114^{\circ}$. These values are in good agreement with those previously found in long-chain compounds. ${ }^{71}$ The mean $\mathrm{C}-\mathrm{H}$ bond distance is $0.96 \AA$ and the mean angle involving hydrogen atoms is $108^{\circ}$. The individual deviations from the average values are quite large as these hydrogen atoms were located from the difference synthesis and their 
Table 3. Fractional atomic coordinates and isotropic temperature factors for the hydrogen atoms.

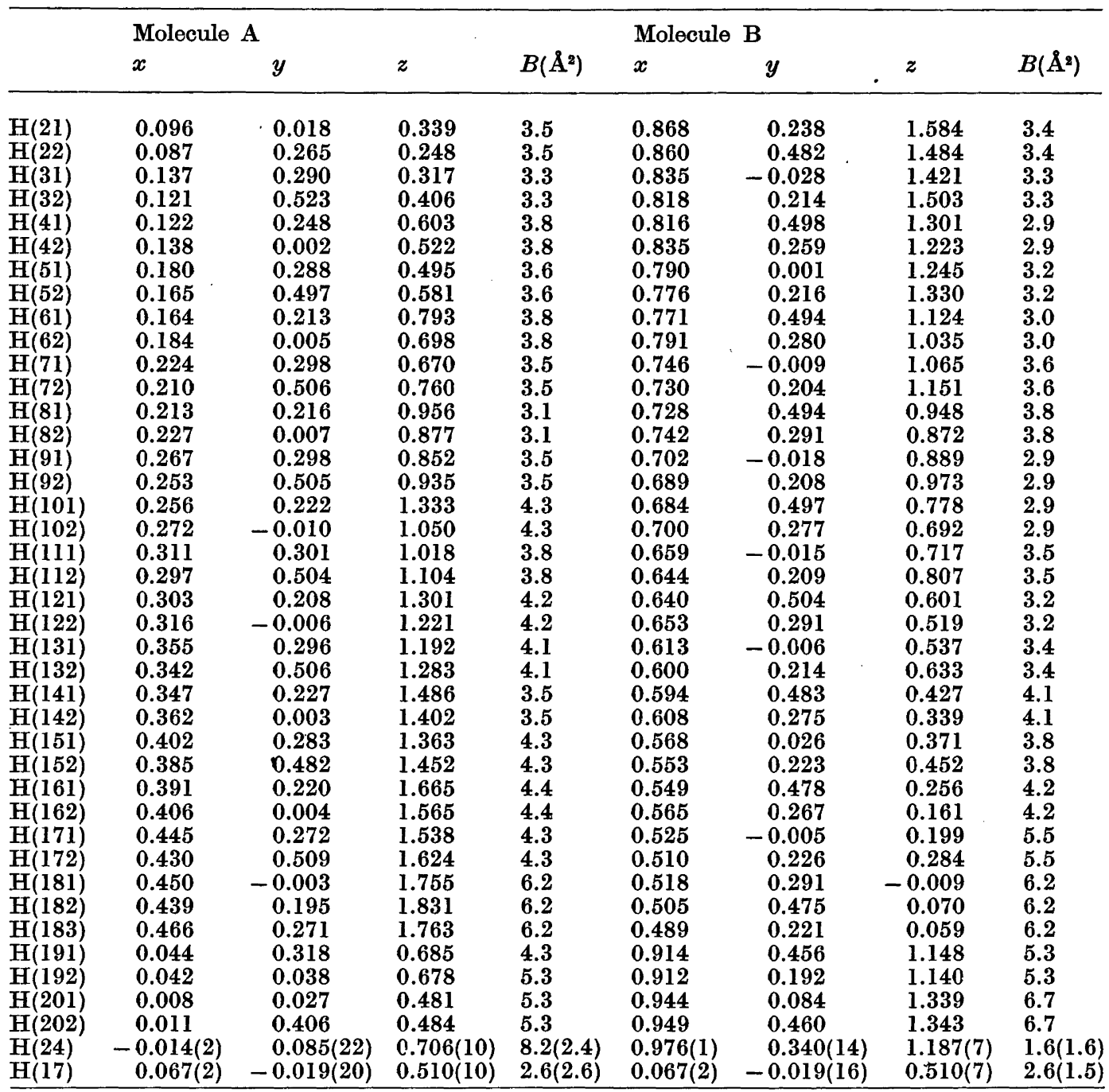

positions never refined. The same mean values were obtained in 13-oxoisostearic acid ${ }^{11}$ in which case the hydrogen atoms were included in the least-squares refinement.

The molecules are V-shaped with a sharp bend at $\mathrm{C}(2)$. The equations for the leastsquares plane through the fatty acid chains are given in Table 4, with the out of plane deviations. The chains are planar from $\mathrm{C}(4)$ to $\mathrm{C}(18)$ within 0.032 and $0.036 \AA$ in molecule $A$ and $B$, respectively. $C(2)$ and $C(3)$ deviate $0.061-0.093 \AA$ from these planes.
The plane through $\mathrm{N}(1), \mathrm{O}(1), \mathrm{C}(1)$ and $\mathrm{C}(2)$ forms an angle with the hydrocarbon chain plane of $84^{\circ}$ in both molecules and intersects the ethanol end group plane [the plane through $\mathrm{N}(1), \mathrm{C}(19), \mathrm{C}(20)$ and $\mathrm{O}(2)]$ at an angle of 85 and $82^{\circ}$ in molecule $A$ and $B$, respectively. The amide plane is thus almost perpendicular to the carbon chain planes. By this arrangement adjacent amide planes are as close as $3.2 \AA$ If, on the other hand, the amide planes were parallel to the ac-plane, this distance would, of course, be $4.89 \AA$. 
Table 4. The best least-squares planes through the stearoyl chains. The planes are calculated from $\mathrm{C}(4)$ to $\mathrm{C}(18)$. The plane equations are $-0.9563 X+0.1592 Y+0.2454 Z-0.0285=0$ and

$-0.9556 X+0.1657 Y+0.2439 Z+0.4205=0$

in molecule $A$ and $B$, respectively. The equations are expressed in terms of the crystal axes.

\begin{tabular}{lcc}
\hline & $\begin{array}{c}\text { Deviations from the } \\
\text { Molecule A }\end{array}$ & $\begin{array}{c}(\AA) \\
\text { Molecule B }\end{array}$ \\
\hline C(4) & -0.007 & 0.036 \\
C(5) & -0.032 & 0.012 \\
C(6) & -0.004 & 0.005 \\
C(7) & -0.009 & -0.010 \\
C(8) & -0.008 & 0.001 \\
C(9) & 0.023 & -0.006 \\
C(10) & 0.019 & 0.008 \\
C(11) & 0.018 & -0.008 \\
C(12) & 0.031 & 0.006 \\
C(13) & 0.018 & -0.026 \\
C(14) & -0.010 & -0.031 \\
C(15) & 0.021 & 0.027 \\
C(16) & -0.009 & -0.001 \\
C(17) & -0.031 & 0.005 \\
C(18) & -0.021 & 0.012 \\
C(1) & 1.271 & -1.190 \\
C(2) & -0.094 & 0.072 \\
C(3) & -0.074 & 0.061 \\
\hline
\end{tabular}

The fatty acid chains are tilted by $55.5^{\circ}$ towards the methyl end group contact planes and thus allow a good packing at the polar part of the molecules. In unbranched longchain compounds the corresponding angle is about $60^{\circ} .12$

The opening angle formed by the fatty acid chain and the direction of maximum extension of the ethanol end group is about
Table 5. The geometry of the hydrogen bonds.

\begin{tabular}{|c|c|c|}
\hline$N(1) A \cdots O(1) A$ & $0,-1$ & $2.87 \AA$ \\
\hline$N(1) A-H(17) A$ & $(0,0$, & 0.76 \\
\hline $\mathrm{H}(17) \mathrm{A} \cdots \mathrm{O}(1) \mathrm{A}$ & $0,-1$ & 2.15 \\
\hline$N(1) B \cdots O(1) B$ & $0, \quad 1$, & 2.80 \\
\hline $\mathrm{N}(1) \mathrm{B}-\mathrm{H}(17) \mathrm{B}$ & $0, \quad 0$ & 0.87 \\
\hline $\mathrm{H}(17) \mathrm{B} \cdots \mathrm{O}(1) \mathrm{B}$ & $(0,1,0) 1$ & 2.01 \\
\hline $\mathrm{O}(2) \mathrm{A} \cdots \mathrm{O}(2) \mathrm{B}$ & $(-1, \quad 0,-1) 2$ & 2.69 \\
\hline $\mathrm{O}(2) \mathrm{A} \cdots \mathrm{O}(2) \mathrm{B}$ & $(-1, \quad 1,-1) 2$ & 2.72 \\
\hline $\mathrm{O}(2) \mathrm{A}-\mathrm{H}(24) \mathrm{A}$ & $0,0) 1$ & 1.22 \\
\hline $\mathrm{O}(2) \mathrm{A} \cdots \mathrm{H}(24) \mathrm{B}$ & $(-1, \quad 1,-1) 2$ & 1.97 \\
\hline $\mathrm{O}(2) \mathrm{B} \cdots \mathrm{H}(24) \mathrm{A}$ & $(1,-1, \quad 1) 2$ & 1.63 \\
\hline $\mathrm{O}(2) \mathrm{B}-\mathrm{H}(24) \mathrm{B}$ & $(0,0,0) 1$ & 0.77 \\
\hline $\mathrm{O}(2) \mathrm{A}-\mathrm{H}(24) \mathrm{A} \cdots \mathrm{O}(2) \mathrm{B}$ & & $141^{\circ}$ \\
\hline $\mathrm{O}(2) \mathrm{A} \cdots \mathrm{H}(24) \mathrm{B}-\mathrm{O}(2) \mathrm{B}$ & & $164^{\circ}$ \\
\hline
\end{tabular}

$a$ The numbers in parentheses indicate transla. tions in the directions $a, b$ and $c$. The 1 or 2 following refer to the equivalent positions $x, y, z$ and $x, \bar{y}, \frac{1}{2}+z$.

$131^{\circ}$. The molecular conformation at the $\mathrm{C}(1)-\mathrm{C}(2)$ bond is shown in Fig. 2. As a comparison the torsion angles at the corresponding bond in tetracosanoylphytosphingosine are also given.

The molecular packing projected on the (llll $\left.\begin{array}{ll}0 & 1\end{array}\right)$ plane is illustrated in Fig. 3. The molecules are arranged head to head in double layers. They are linked together by two hydrogen bonds running in the $b$ axis direction, one connecting molecules within the layers and the other between molecules in different layers. The existence of these hydrogen bonds was also confirmed by the characteristic shifts in the infrared spectrum of the compound in the solid state as compared to that in solution. The geometry around the hydrogen bonds is given in Table 5 and a detailed picture of the

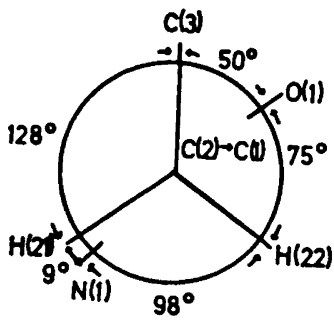

(a)

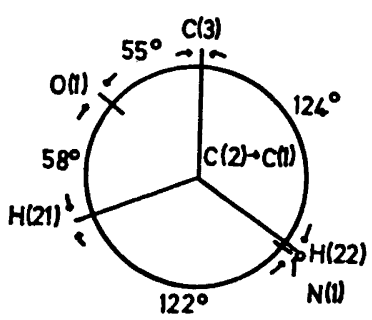

(b)

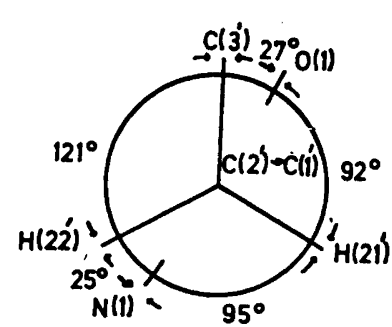

(c)

Fig. 2. The conformation around the first bond in the fatty acid chain in (a) molecule A, (b) molecule $\mathrm{B}$ in $N$-(2-hydroxyethyl)-octadecanamide, (c) tetracosanoylphytosphingosine. 


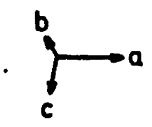

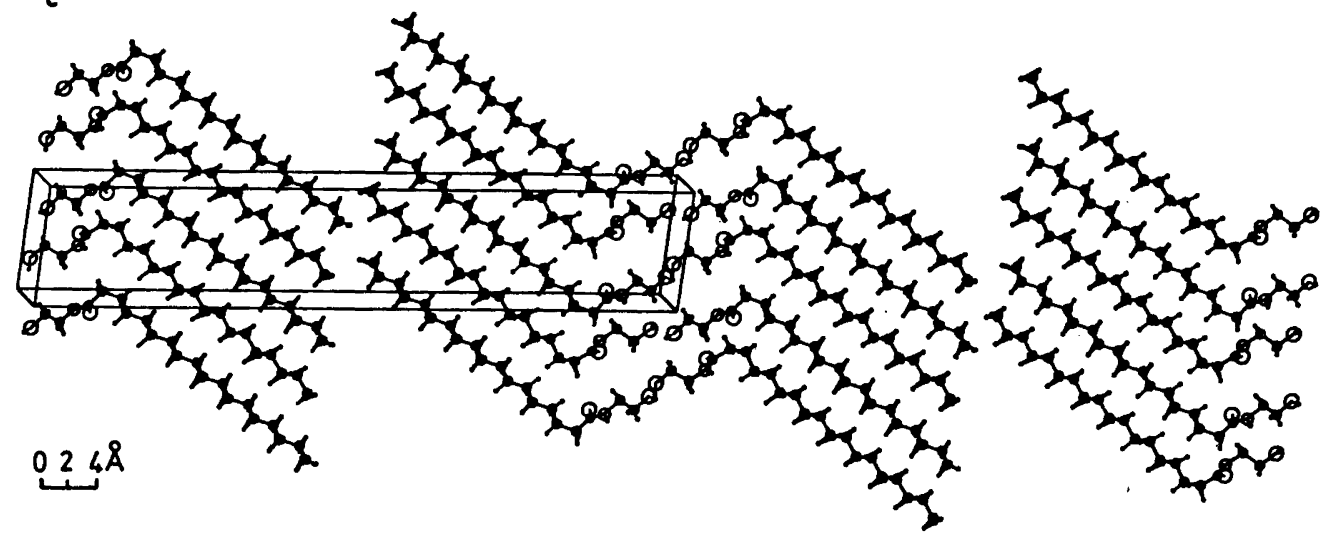

Fig. 3. The molecular packing seen along the $b$ axis.

packing at the polar part in Fig. 4. The $\mathrm{N} \cdots \mathrm{O}$ hydrogen bond distances are 2.87 and $2.80 \AA$ respectively. Reported values for $\mathrm{N} \cdots \mathrm{O}$ contacts in other long-chain compounds are $2.80 \AA$ in triacetylsphingosine ${ }^{13}$ and $2.98 \AA$ in tetracosanoylphytosphingosine.

The other hydrogen bond connects the hydroxyl oxygens in molecule $\mathbf{A}$ and molecule $\mathbf{B}$ so that every oxygen atom takes part in two hydrogen bonds running almost parallel to the $b$ axis. A similar arrangement of hydrogen bonded hydroxyl oxygens has been found in 11-bromoundecanol. ${ }^{14}$ The $0 \cdots 0$ contacts are 2.69 and $2.72 \AA$, respectively, which are in good agreement with those found in tetracosanoylphytosphingosine. The arrangement

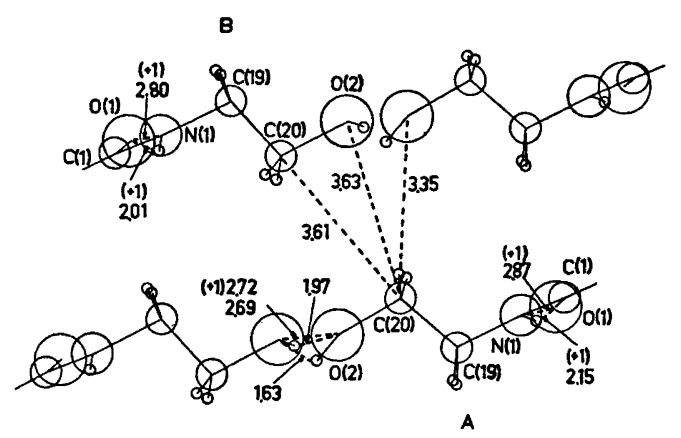

Fig. 4. The polar contact region viewed along the $b$ axis with the shorter intermolecular contacts indicated. in the van der Waals contact planes is shown in Fig. 5. The shortest methyl carbon contact is $3.95 \AA$. The closest interlayer hydrogenhydrogen contacts are $\mathrm{H}(183) \mathrm{A} \cdots \mathrm{H}(183) \mathrm{B}$ and $\mathrm{H}(181) \mathrm{A} \cdots \mathrm{H}(183) \mathrm{B}$ (in the molecule symmetry related by a glide plane) which are 2.83 and $2.85 \AA$, respectively.

The hydrocarbon chains pack according to the common orthorhombic subcell packing $(\mathrm{O} \perp){ }^{15}$ The subcell dimensions are $a_{\mathrm{s}}=4.89$, $b_{\mathrm{s}}=7.43, c_{\mathrm{s}}=2.55 \AA$ and the volume per $\mathrm{CH}_{2}$ group is $23.2 \AA^{3}$.

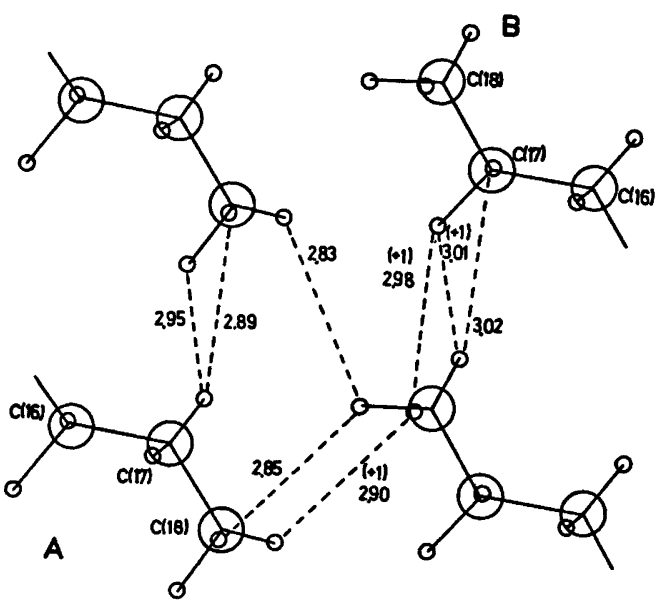

Fig. 5. The methyl end group contacts as seen along the $b$ axis with the shorter hydrogenhydrogen interactions given.

Acta Chem. Scand. A 31 (1977) No. 4 
We are grateful to Professor S. Abrahamsson for helpful discussions and Mrs. M. Varju for technical assistance. Grants in support of this Department were obtained from the Swedish Medical Research Council, the Swedish Board for Technical Development, the Wallenberg Foundation and the U.S. Public Health Service (GM-11653).

\section{REFERENCES}

1. Kuel, F. A., Jacob, T. A., Ganley, O. H., Ormond, R. E. and Meisinger, M. A. P. J. Am. Chem. Soc. 79 (1957) 5577.

2. Karlsson, K.-A., Samuelsson, B. E. and Steen, G. O. Acta Chem. Scand. 22 (1968) 2723.

3. Karlsson, K.-A., Samuelsson, B. E. and Steen, G. O. Acta Chem. Scand. 21 (1967) 2566.

4. Stoffel, W., Sticht, G. and LeKim, D. Hoppe-Seyler's Z. Physiol. Chem. 349 (1968) 1149.

5. Wren, J. J. and Merryfield, D. S. Biochim. Biophys. Acta 98 (1965) 589.

6. Nilsson, B. and Pascher, I. Private communication.

7. Dahlén, B. and Pascher, I. Acta Crystallogr. $B 28$ (1972) 2396.

8. O'Connell, A. M. Acta Crystallogr. B 29 (1973) 2320.

9. International Tables for X-Ray Crystallog. raphy, Kynoch Press, Birmingham 1962, Vol. III, pp. 201-209.

10. Stewart, R. F., Davidson, E. R. and Simpson, W. T. J. Chem. Phys. 42 (1965) 3175.

11. Dahlén, B. Acta Crystallogr. B 28 (1972) 2555.

12. von Sydow, E. Ark. Kemi 9 (1956) 231.

13. O'Connell, A. M. and Pascher, I. Acta Crystallogr. B 25 (1969) 2553.

14. Rosén, L. and Hybl, A. Acta Crystallogr. B 28 (1972) 610 .

15. Abrahamsson, S., Ställberg-Stenhagen, S. and Stenhagen, E. Prog. Chem. Fats Other Lipids 7 (1963) 60.

Received December 1, 1976. 